\title{
LA RESTAURACIÓN DE LA COMPAÑÍA DE JESÚS BAJO EL RÉGIMEN DE FRANCO EN 1938
}

\author{
JORGE GARCÍA OCÓN ${ }^{1}$
}

Fecha de recepción: mayo 2019

Fecha de aceptación y versión definitiva: octubre 2019

RESUMEN: El presente artículo pretende analizar la restauración de la Compañía de Jesús en 1938 por parte del Gobierno de Burgos. Se atiende tanto al proceso que se siguió como al ambiente que lo rodeó y la postura de los diferentes protagonistas que intervinieron en el mismo. Se trata de un proceso acontecido en medio de la guerra civil española y en plena construcción del llamado nuevo Estado, lo que explica las dificultades con las que tuvo que enfrentarse el decreto que el conde Rodezno presentó ante el Consejo de Ministros.

Palabras clave: Restauración; Compañía de Jesús; 1938; Iglesia Católica; España.

\section{The Restoration of the Society of Jesus by Franco's Government in 1938}

ABSTRACT: The article strives to analyse the restoration of the Society of Jesus by the Burgos Government in 1938. It also provides a close look at both the process and circumstances of the event, as well as the opinions of many of the people involved. The process took place after the first half of the Spanish Civil War, right at the time when the "new state» was being formed, which explains the many difficulties Rodezno's decree faced when it was presented to the Council of Ministers.

KEY WORDS: Restoration; Society of Jesus; 1938; Catholic Church; Spain.

1 Profesor en el CES Villanueva y en la Universidad CEU San Pablo. Correo electrónico: jorgegarciaocon@hotmail.com. 


\section{ANTECEDENTES}

En 1936, la situación de la Compañía de Jesús en España era la de una institución religiosa disuelta, cuyos miembros tenían prohibido manifestarse como tales y que se veían obligados a actuar en la clandestinidad. Jurídicamente no existía y sus propiedades habían sido incautadas por el gobierno de la República. Larga era la historia de expulsiones y disoluciones de la orden fundada por San Ignacio, no solo en España sino en toda Europa. Sin embargo, en esta ocasión parecía algo exclusivo.

La Compañía de Jesús fue disuelta por el artículo 26 de la Constitución de 1931 y por el Decreto de disolución de la Compañía de Jesús, publicado en la Gaceta de Madrid el 24 de enero de 1932. En cuanto al porqué, las causas del antijesuitismo en España son tratadas por Verdoy (1995, pp. 34-38)2. Explica cómo el origen de este fenómeno estaba en las obras del ex jesuita Miguel Mir (Jesuitas de puertas adentro o un barrido hacia fuera de la Compañía de Jesús, Barcelona, 1986) y Jaime Torrubiano y Ripoll (Beatería y religión, Madrid, 1924), entre otras. Obras ampliamente extendidas y leídas en las postrimerías de la II República, en las que se describía a los jesuitas españoles como especuladores, amigos de los ricos que se desentendían de sus deberes con los pobres, o codiciosos de poder, entre otras calificaciones. Sin embargo, estas obras no bastan para explicar como la animadversión hacia los jesuitas se extendió entre las clases populares. Como suele suceder habitualmente lo escrito actúa de altavoz de un sentir que hay antes en la sociedad. Un sentir que se había construido tal como explica García Cortázar (2006, pp. 15-19) a base de prensa, discursos de anarquistas, republicanos, representaciones teatrales, o novelas. Un estado de opinión que fomentó un anticlericalismo, dentro del que el antijesuitismo tenía un espacio considerable. ¿Por qué? Lo explica bien Revuelta González (2014, pp. 45-58) al señalar que los jesuitas españoles tendieron a alinearse, a lo largo del siglo XIX y la primera mitad del siglo XX, con los sectores conservadores de la sociedad, debido al ataque sufrido por los liberales más radicales: la Compañía de Jesús había sido disuelta anteriormente en 1820, 1835 y 1868. Las razones de estos ataques quizá se encuentren en la nebulosa de causas de la disolución de la Compañía de Jesús en 1773 por el papa Clemente XIV y en cómo el proyecto liberal de transformar la sociedad española chocaba con la presencia de la Compañía. En fin, todo este conjunto de hechos llevó a que

\footnotetext{
2 A parte de la obra de Verdoy, para un mejor conocimiento de la disolución e incautación de la Compañía de Jesús durante la Segunda República, ver Batllori, 1976, pp. 394-403.
} 
a la altura de los años 30 fueran odiados o temidos por muchos y, por tanto, provocasen un sentimiento de rechazo.

Vistas las motivaciones del antijesuitismo, ¿cuáles fueron las razones esgrimidas por las autoridades republicanas para disolver la Compañía de Jesús? Los jesuitas fueron disueltos como orden religiosa, con la excusa, por un lado, de que estatutariamente imponían un voto oficial de «obediencia a una autoridad distinta a la legítima del Estado». Por otro lado, y en la línea de preservar la salud pública, los jesuitas suponían un obstáculo al sistema de enseñanza estatal que se pretendía imponer, así como a la reforma de la sociedad que desde la izquierda republicana pretendía realizarse.

El Decreto de disolución imponía el cese de la vida en común, en el término de diez días; prohibía a los jesuitas convivir, reunirse o asociarse; los bienes, incluidos los mobiliarios depositados en Bancos, etc., pasaban a propiedad del Estado, que los ocupó inmediatamente. Sólo las iglesias se cedieron en uso a los ordinarios de las diócesis, "a condición de no emplear en el servicio de los citados templos a individuos de la disuelta Compañía».

Sin embargo, a pesar de la disolución llevada a cabo por las autoridades, la Compañía de Jesús siguió actuando clandestinamente en España. En estas circunstancias, disuelta y actuando de forma ilegal, llegó el golpe de Estado de julio de 1936.

\section{CONTEXTO}

Como ya se ha mencionado, parece ser que la Iglesia se mantuvo al margen de lo que sucedía en las primeras jornadas del alzamiento del 17 de julio. Conviene detenerse en lo que fueron las relaciones de la Iglesia (obispos españoles, jesuitas, Santa Sede, clero extranjero...), ya que marcaron las circunstancias en las que se produjo la restauración de la Compañía y ayudan a comprender cómo fue el proceso.

¿Qué expectativas se tenía desde la Compañía de Jesús hacia los sublevados? ¿Qué pensaban que podían esperar de los constructores del llamado Nuevo Estado? En octubre de 1936, la opinión era bastante favorable. En carta del P. General a todos los Provinciales, comparaba la situación de fervor religioso por parte de los sublevados de quienes decía «creen que luchan por la religión y la patria y por la cultura cristiana», con las matanzas llevadas a cabo en zona republicana contra religiosos (aunque la Compañía de Jesús había recibido pocas palmas en comparación con otras órdenes religiosas a causa de su exilio anticipado) ( De los padecimientos que los 
Nuestros de España sufren por Cristo», 1936, pp. 557-559). En la zona que quedó bajo control republicano, fueron numerosos los casos de destrucción de iglesias, persecución y asesinato de clérigos por el hecho de serlo. Al margen de una valoración propia sobre los ataques recibidos por parte de la Iglesia en la zona de control republicano, resulta de mayor interés conocer la valoración de los propios protagonistas afectados. Estos percibieron dichos ataques como una persecución contra todo lo que tuviera que ver con la Iglesia. La persecución sufrida por la Compañía cuenta también con numerosos testimonios, en los que se refleja cómo la persecución contra jesuitas comenzó el mismo día en que se produjo el intento frustrado de sublevación militar ${ }^{3}$. Del relato del martirio que sufrieron los jesuitas de la Academia de María de Molina, el 7 de agosto de 1936, se recoge el siguiente pasaje que ilustra perfectamente la razón por la que eran matados:

Sobre las diez de la noche del día 9 de agosto (a lo que recuerdan), estando cenando, sintieron dos tiros. "Un besugo que ha caído» El H. Montero, frente al colegio. Estuvo hasta media tarde del día siguiente con un letrero: «Por jesuita». (de Frutos Herranz, 1939)

Esta visión del P. Ledochowski en los primeros meses de guerra la exponía bien el P. Alba al señalar que «mientras en unas partes se incendian las iglesias, en otras se ven abarrotadas de gente que pide perdón a Dios y ruega por el triunfo de la causa de los buenos; mientras en una parte se asesina a los sacerdotes y religiosos, en otras se les besa públicamente la mano en señal de respeto y veneración; mientras unos mueren maldiciendo de Dios, otros mueren gloriosamente gritando: ¡Viva Cristo, Viva España!»(Alba, s. f.). Recogía el P. Alba manifestaciones concretas de fervor, especialmente de jóvenes, en Navarra, Cádiz, Salamanca, Badajoz... Pongamos aquí, no obstante, otra relatada por el P. Encinas de un padre navarro que al alistarse dejaba 7 hijos: «El que mis hijos se queden sin padre no me aterra; lo que me aterra es que se queden sin catecismo» (Encinas, 1936). En otra carta escrita en septiembre por el P. Juan Martínez, que servía como sacerdote en el $2^{\circ}$ Batallón del Regimiento "La Victoria», en Guadarrama, se hablaba de numerosas confesiones y comuniones (Martínez, 1936). Eran meses de gran

3 Sobre la persecución de jesuitas, ver: («De los padecimientos que los Nuestros de España sufren por Cristo», 1936), (de Frutos Herranz, 1939), (Márquez, 1936), («P. José María Alegre», 1940), («La vida en la zona roja. La casa de escritores, de Madrid», 1940a), («La vida en la zona roja. La casa de escritores, de Madrid», 1940b), («Nuestros mártires. P. Fernández Díaz-Masa», 1940), («La vida en la zona roja», 1940a), («La vida en la zona roja», 1940b), («La vida en la zona roja», 1940c), (Llanos, s. f.). 
optimismo y así lo manifestaba el Cardenal Gomá en carta al P. Ledochowski el 13 de septiembre cuando le afirmaba que la guerra estaría prácticamente terminada en enero y que la restauración que se había hecho en Navarra de la Compañía de Jesús ${ }^{4}$ pronto se haría en toda España (Andrés-Gallego \& Pazos, 2010, pp. 133-136). En otra carta, esta vez al Cardenal Pacelli, le expresaba su convencimiento en que las leyes anticlericales de la República serían pronto derogadas («Carta del Cardenal Gomá al Cardenal Pacelli. 11/ XII/1936», 2010). Sin embargo, la guerra no tocaría a su fin tan rápido y la restauración de los jesuitas debería esperar algún tiempo más.

Otro hecho que demuestra la buena sintonía y colaboración de la Compañía de Jesús con la causa de los sublevados fue el que varios jesuitas, siguiendo el mandato papal de mantener un servicio de propaganda anticomunista en todo el mundo, difundieron una buena imagen de los llamados nacionales en la prensa internacional. Evidencias que prueban esto pueden encontrarse entre la correspondencia de Gomá, en la que queda claro la identidad de puntos de vista del cardenal con los jesuitas españoles y el propio Prepósito General de la Compañía. En noviembre de 1936, le escribía el P. Francisco Javier SJ insistiéndole sobre la conveniencia de que viajase a Roma (Andrés-Gallego \& Pazos, 2010a) ${ }^{5}$ para dar una correcta imagen de lo que en España estaba sucediendo, ya que algunos elementos vascos y catalanes estaban desvirtuando esa imagen, al igual que lo estaban haciendo en París (Andrés-Gallego \& Pazos, 2010c). Otros jesuitas dedicados a esta labor durante toda la guerra fueron los PP. José Torra (en Avigliana), Aurelio Yanguas (en Lovaina y Marneffe), Domingo Mayor (en Roma), Conesa (en Dublín), Arrupe (en EE. UU.), Guizard (Bordeaux). Todos ellos mantuvieron una correspondencia activa con Gomá informándole del estado de opinión en diferentes países y solicitando información para poder contrarrestar los esfuerzos que la propaganda enemiga llevaba a cabo incluso desde medios católicos. El P. Constantino Bayle S.J., por petición del cardenal Gomá se encargó entre agosto y diciembre de 1937 de promocionar la creación de una Oficina de Información Católica entre los superiores de las órdenes religiosas. A este requerimiento, el General de la Compañía respondió poniendo al servicio de esa oficina todas las revistas jesuíticas (Andrés-Gallego \& Pazos, 2006c). El 8 de enero de 1938, Gomá escribía al P. Ledochowski para agradecerle la labor de propaganda realizada por la Compañía de Jesús (Andrés-Gallego \& Pazos, 2006a).

4 El Decreto de la Diputación foral de Navarra databa del 15 de agosto de 1936.

5 Lo haría el 8 de diciembre. 
Queda claro que había un sentimiento de adhesión hacia la causa de los sublevados por parte de la Compañía de Jesús. Sin embargo, en 1937 comenzaron a surgir algunas dudas sobre el futuro político, lo que no hizo que los jesuitas españoles dejaran de trabajar por la causa ${ }^{6}$. En una carta del P. Antonio Encinas (Nota de A. Encinas SJ, s. f.) recogía un informe llamado nota B de «una persona de bastante buen juicio y bastante bien situada como para saber lo que pasa», con la que decía comulgar en lo que exponía. El informe explicaba las razones por las que era imposible que el futuro de España fuera el de un Estado teológico: un ambiente social muy descristianizado, la oposición de Falange, la transigencia del partido carlista, el rechazo de las naciones aliadas de los sublevados y, sobre todo, el desinterés por un proyecto así de Franco y el resto de los mandos militares. Claro está que por parte de las autoridades no se exponía una negativa públicamente, pues se estaba buscando en esos momentos el reconocimiento por parte de la Santa Sede al Gobierno de Burgos. Con todo, España no sería un Estado teológico, pero tampoco uno anticatólico. Antes bien, la expectativa era que el Estado garantizase medios a la Iglesia para formar al pueblo español en la fe católica. Sin embargo, Encinas veía en Falange un serio peligro por estar formado por intelectuales que consideraba «de tipo laicista». Entendía que para combatir esta amenaza la Iglesia debía influir en el Estado, concretamente «en sus elementos personales de máximo influjo». Para ello, el echar mano de Acción Católica no era suficiente, pues no permitía una acción coordinada como la de los laicistas. Proponía la constitución de un Comité central, formado por personas que no pertenecieran a ningún partido político, que se encargaría de coordinar la labor de atraer en todas partes a los elementos más influyentes hacia las posturas de la Iglesia.

De todos los obstáculos a sus proyectos que la Iglesia empezaba a advertir en 1937, el mayor era la creciente influencia del nazismo y de Falange. Ya en su informe de octubre del 36, Gomá le había señalado al Cardenal Pacelli la conveniencia de tratar de influir lo máximo en las milicias formadas por falangistas con el fin de evitar desviaciones futuras (Andrés-Gallego \& Pazos, 2010d). ${ }^{7}$ Entretanto, a finales de ese mismo año ya podía vislumbrarse claramente que la Iglesia deseaba principalmente la derogación de la legislación anticlerical de la República y que Franco pretendía un posicionamiento más claro en su favor por parte de la Santa Sede. En el informe de marzo de

6 En septiembre de 1937, la Carta Colectiva fue activamente difundida por los jesuitas en todo el mundo, siguiendo las órdenes de su P. General (Andrés-Gallego \& Pazos, 2005b).

7 En julio el P. Recalde SJ proponía a Gomá la elaboración de un manual para inculcar la doctrina católica entre los falangistas (Andrés-Gallego \& Pazos, 2004b). 
1937 a la Santa Sede, relata Gomá su reunión con Franco, quién le dijo las siguientes palabras en cuanto a la derogación de la legislación anticlerical: «Yo deseo tanto como la Iglesia raer de la legislación española cuanto sea atentatorio a la conciencia católica del país; pero, primero, no me parece oportuno derogar leyes tan fundamentales sin la solemnidad análoga a la que las creo; y en segundo lugar, me veo ahora precisado a tratar, en España [falangistas] y fuera de ella [nazis], con gentes cuyo concurso necesito y que podrían recelar, desde sus puntos de vista, de una actuación demasiado rápida en el sentido que Su Eminencia me indica» (Andrés-Gallego \& Pazos, 2002). Estaba claro, Franco necesitaba a Falange, la ayuda de Hitler y el reconocimiento y lealtad de la Iglesia (lo que incluía no solo al clero español, sino al de todo el mundo) y quería tenerlos a todos contentos. Para ello pedía paciencia al clero mientras domesticaba a los falangistas. Paciencia que habría de durar mucho tiempo, pues los problemas de la Iglesia con Falange continuaron algunos años más ${ }^{8}$.

La documentación de la época deja claro que ya en 1937 fue calando en la conciencia del clero español el peligro que entrañaba la influencia del nazismo en España, según se iban recibiendo noticias del trato que el catolicismo recibía en Alemania. El problema fue nuevamente cuestión de oportunidad. Cuando, desde la Secretaría de Estado de la Santa Sede, el Cardenal Pacelli solicitó a los obispos españoles la difusión de la encíclica Mit brennender Sorge, que condenaba el nazismo, se tomó la decisión de publicarla en los boletines oficiales de cada diócesis. Sin embargo, pronto se reculó. Debido a presiones que llegaban desde la autoridad civil, se tomó la decisión de retrasar la publicación de forma oficial ${ }^{9}$. Nuevamente la Iglesia debía tener

8 Durante el resto de 1937 y en 1938, las tensiones con Falange continuaron en distintos ámbitos: el intento del Sindicato Español de Magisterio de absorber y eliminar a la Federación de Maestros Católicos; el intento de monopolizar la prensa infantil mediante el periódico Flecha (falangista y difusor de una ideología patriótica pagana) y quitar de en medio al periódico Pelayos (difusor de un patriotismo tradicional católico).

9 En 1937, Gomá se había dado cuenta de que muchos falangistas eran pronazis por lo que la publicación de la encíclica Mit brennender Sorge (dada por Pío XI el 14 de marzo de 1937) podía suponer un inconveniente para que el proyecto de unificación de partidos y milicias nacionales tuviese éxito, más cuando existían tensiones entre falangistas y tradicionalistas. Esta decisión fue ratificada posteriormente en la Conferencia de Metropolitanos celebrada en la abadía cisterciense de Dueñas (Palencia), entre el 10 y el 13 de noviembre de 1937. Se acordó difundir de forma «fragmentaria y por los diversos procedimientos de publicidad aquellas partes de la encíclica que sean más apropiadas a nuestra situación actual, mientras se espera la oportunidad de divulgarla en la totalidad de su texto» (Cárcel Ortí, 1994). ¿Por qué sólo publicarla en parte? De lo visto en la correspondencia de la época se deduce 
paciencia. No se trataba como le insinuó Pizzardo a Gomá de que Franco tuviera una orientación hitleriana o fascista (lo que Gomá negó en varios informes a la Santa Sede), sino que Franco necesitaba la ayuda de Hitler y Falange, aunque no compartiera sus proyectos (Andrés-Gallego \& Pazos, 2003). Sin embargo, era algo que costaba entender a muchos católicos fuera de España. Para la Compañía de Jesús en Alemania los años 30 fueron de lucha. Allí no fue suprimida como en España, ya que Hitler entendió que la Iglesia católica sería un enemigo demasiado poderoso por la influencia que ejercía sobre la conciencia de muchas almas alemanas. Sin embargo, no hubo cooperación entre Iglesia y Estado. En un principio, ambos trataron de no hacerse daño mutuamente; pero pronto las diferencias empezaron a generar conflictos. Con la llegada de la guerra, en consonancia con la Santa Sede, la Compañía de Jesús cooperaría activamente en la resistencia contra el nazismo. Antes de la llegada de Hitler al poder en enero de 1933, algunos jesuitas habían denunciado la ideología nacionalsocialista. Tras el ascenso a la cancillería siguió la lucha intelectual contra el Estado, desde publicaciones escritas y desde los púlpitos. Éste reaccionó rápidamente: las revistas fueron prohibidas, las casas incautadas, las comunidades proscritas, a muchos se les prohibió predicar, otros fueron a dar con sus huesos en la cárcel o en campos de concentración y un buen número fueron ejecutados acusados de traición o en nombre de la eutanasia. Paralelamente, las asociaciones juveniles de la Iglesia, entre ellas las Congregaciones Marianas, fueron reducidas a grupos insignificantes sin apenas influencia. A medida que los años fueron pasando, más y más casas fueron incautadas. El objetivo estaba claro: limitar hasta el ridículo los medios de la Iglesia para propagar su fe. En fin, la reacción en Alemania a la Carta Colectiva no fue la deseada por el episcopado español. Para los católicos alemanes, perseguidos por los nazis, el hecho de que Franco fuera ayudado por Hitler significaba que también perseguiría a la Iglesia. En enero de 1938, la encíclica Mit brennender Sorge fue publicada por los jesuitas en Razón y Fe, que había vuelto a publicarse en septiembre de 1937. Esto hizo que Gomá cambiase de criterio sobre la difusión de la encíclica, aunque algunos obispos la seguían considerando inoportuna. En el mismo mes de enero se publicó en el boletín eclesiástico de Toledo, diócesis de la que era titular Gomá.

El punto más delicado de toda esta cuestión a lo largo de 1937 estuvo marcado por la prudencia de la Santa Sede a la hora de dar su bendición a

que pretendía no provocar enfrentamientos con algunos dirigentes pertenecientes a Falange favorables al nazismo. ¿Por qué sí publicar algunas partes? Porque por parte de esos mismos dirigentes y algunos escritores se estaba contaminando la religión católica con ideas del nazismo pagano y racista. 
la causa de los blancos. A pesar de los informes favorables de Gomá sobre Franco y su defensa a ultranza de que la suya era la causa de los católicos, el reconocimiento oficial de la Santa Sede no acababa de llegar. Desde Roma se recelaba por la ayuda que los sublevados recibían de Alemania, un país desde el que, hacía tiempo, llegaban cada vez más noticias inquietantes del trato a los católicos. Este hecho era aprovechado por los propios alemanes para prevenir a las autoridades españolas contra Roma. El problema se hacía mayor por las críticas recibidas desde medios católicos extranjeros, por el hecho de que en el Vaticano se prestase oído a lo que algunos sacerdotes nacionalistas vascos decían ${ }^{10}$, y por la influencia ejercida por algunos de los dirigentes de A.C. y los Propagandistas, de los que se pensaba actuaban contra los intereses de la causa nacional. La creciente influencia alemana y de Falange se empezó a advertir en algunas disposiciones del gobierno. La tardanza del apoyo solicitado por Franco a Roma, creó un cierto movimiento antivaticanista entre los falangistas, autores del eslogan «¡Católicos sí; vaticanistas, no!» (Marquina Barrio, 1985, pp. 39-52), lo que puso en guardia a la jerarquía eclesiástica. A la altura de junio, Gomá valoraba así la situación: "En general, se nota toda una desviación del sentido profundamente religioso que tuvo en sus principios el movimiento y una disminución de la devoción a la Santa Sede, tan tradicional en el pueblo español» (AndrésGallego \& Pazos, 2004a). En septiembre cambió un poco la situación. Tras el reconocimiento oficial por parte de la Santa Sede al marqués de Aycinena como Encargado de Negocios ante el Vaticano, las relaciones parecieron mejorar dándose algunas muestras de deseos de colaboración por parte de Serrano Suñer, Secretario político general de la FET (Andrés-Gallego \& Pazos, 2005a).

En el verano de 1937, la causa de los blancos era apoyada por la totalidad de la Compañía de Jesús, tanto en España como fuera. Únicamente, algunos jesuitas franceses hicieron algunas publicaciones críticas, que fueron rápidamente censuradas por el propio P. General ${ }^{11}$. No obstante, desde el clero francés se mantuvo en general una actitud crítica con los dos bandos de la guerra española. La campaña contra los sublevados en Francia desde el catolicismo se debió a la influencia que ejercían algunos católicos vascos

10 El Osservatore (concretamente su director Giuseppe dalla Torre di Sanguinetto) equiparaba la violencia contra la Iglesia en ambos bandos. Esta opinión era influida también por los círculos democristianos de París.

11 A estos se unirían en 1938 algunos jesuitas austriacos huidos a Suiza tras el Anschluss. Atacaban a Franco por ser amigo de Hitler. 
exiliados al sur de Francia ${ }^{12}$, un grupo de políticos republicanos en París que se hacía llamar «España cristiana» ${ }^{13}$ y la Embajada republicana (que lanzaba folletos advirtiendo a los franceses del peligroso influjo del neopagano Hitler sobre Franco y los suyos) (Andrés-Gallego \& Pazos, 2005d).

Con todo, desde las autoridades de la Compañía siempre se tuvo un buen concepto de Franco. El 5 de julio de 1937, Ledochowski escribía a Pacelli informándole del contenido de una entrevista que el P. Pérez del Pulgar había tenido con Franco, en la que le aseguraba que la Iglesia debía desempeñar un papel importante en el futuro de España. El 19 de julio de 1937, Ledochowski escribía a Pacelli adjuntándole una carta, del 3, del P. Cayuela SJ al P. Mundó SJ afirmando con muchos detalles la religiosidad de Franco (Cárcel Ortí, 2017, pp. 388-391, 421-426). A esto se unía el que nunca concedieron credibilidad a la versión de los sacerdotes nacionalistas vascos. El 30 de abril de 1937, Ledochowski escribía a Pacelli adjuntándole un informe titulado «Notas sobre el aspecto religioso de la guerra civil en Vizcaya», cuyo autor no se identificaba por prudencia, pero al que Ledochowski concedía credibilidad. El informe venía a señalar la endeble posición en que se encontraba el clero nacionalista vasco entre el más que probable futuro castigo de los militares y el latente desbordamiento de los rojos. No era verdad que no se hubiese ejecutado a sacerdotes en Euskadi, pues varios lo habían sido en cárceles flotantes por ser antinacionalistas (si bien, tras la aprobación del estatuto de autonomía vasco, se tuvo más cuidado para atraerse el apoyo de los católicos). El gobierno vasco justificaba su postura en la guerra argumentando que luchaba contra el fascismo pagano en defensa del catolicismo; que el catolicismo español estaba corrompido y era fariseo por haberse vendido al capitalismo. Su postura real era que una guerra podría dinamitar España y así conseguir la independencia como pago de la República por su ayuda (Cárcel Ortí, 2017, pp. 388-391, 182-188).

\section{RESTAURACIÓN}

La Compañía de Jesús fue readmitida oficialmente en la zona de España gobernada por Franco mediante Decreto del 3 de mayo de 1938 (BOE), por el que se derogaba el Decreto de 23 de enero de 1932 sobre disolución de la

12 En varias diócesis francesas se organizaban colectas en favor de católicos vascos refugiados para ganarse la simpatía del Frente Popular.

13 Entre otros formaban este grupo Mendizabal, Madariaga, Roca, Caball, Dencas, Puig, Cadafalch, Alcalá Zamora, Maura y Portela, quienes actuaban de acuerdo con Indalecio Prieto (Andrés-Gallego \& Pazos, 2005c). 
Compañía de Jesús e incautación de sus bienes y en su virtud, la Compañía de Jesús tenía plena personalidad jurídica y podría libremente realizar todos los fines propios de su Instituto, quedando, en cuanto a lo patrimonial, en la situación en que se hallaba con anterioridad a la Constitución de 1931. Por la Ley del 2 febrero 1939 (BOE) las Ordenes Religiosas recobraban la situación jurídica que tenían en España con anterioridad a la Constitución de 9 de diciembre de 1931. Por una Orden ministerial (publicada en el BOE el 27 enero 1940, p. 697 s), se concretaba la devolución de las propiedades a la Compañía de Jesús. Atrás quedaba un duro período de supresiones y persecuciones: en 1820 eran suprimidos con la llegada del Trienio Liberal, tras haber sido restaurados en 1815 por Fernando VII, un año después de que Pío VII lo hiciera en la Iglesia; vueltos en 1823, nuevamente eran suprimidos en 1835, tras haber sufrido justo el año antes 15 muertos en la «matanza de frailes» de Madrid; volvían a la normalidad en 1851, para volver a ser suprimidos en 1868; la nueva era canovista les devolvería a la normalidad hasta la llegada de la legislación de la Segunda República.

En esta situación, por parte de la Compañía de Jesús, no cabe duda de que la causa de los sublevados fue especialmente bien acogida por ésta, cuyos miembros exiliados se incorporaron a la España Nacional desde 1936. Cuando la Compañía de Jesús fue readmitida oficialmente, lo fue con devolución de sus derechos y de sus bienes. Es decir, Franco restauró a la Compañía de Jesús jurídicamente, devolviéndole su patrimonio. Ya en 1933, siendo gobernador militar de Baleares, Franco había manifestado al obispo de Palma de Mallorca su repulsa ante la ley contra las congregaciones religiosas; como el año anterior ante los jesuitas de Oviedo, a los que visitó para mostrar su desacuerdo con la disolución (Verd, 2001, p. 1519). En el decreto podían leerse las razones de su readmisión:

[...] De este despertar glorioso de la tradición española forma parte principal el restablecimiento de la Compañía de Jesús en España, en la plenitud de su personalidad, y éste por varias razones. En primer término, para reparar debidamente la injusticia contra ella perpetrada.

En segundo lugar, porque el Estado Español reconoce y afirma la existencia de la Iglesia católica como sociedad perfecta en la plenitud de sus derechos y, por consiguiente, ha de reconocer la personalidad jurídica de las órdenes religiosas canónicamente aprobadas, como lo es la Compañía de Jesús desde Paulo III y posteriormente por Pío VII y sus sucesores.

En tercer término, por ser una orden eminentemente española y de gran sentido universal, que hace acto de presencia en el cénit del Imperio español, participando intensamente en todas sus vicisitudes, por lo que, con feliz coincidencia, caminan siempre juntos en la historia las persecuciones contra ella y los procesos de desarrollo de la anti-España. 
Y, finalmente, por su enorme aportación cultural, que tanto ha contribuido al engrandecimiento de nuestra Patria y a aumentar el tesoro científico de la humanidad, por lo que Menéndez Pelayo calificó su persecución de «golpe mortífero para la cultura española y atentado brutal y oscurantista contra el saber y las letras humanas».

(Nuestra Casa, 1984, pp. 147-148)

Razones jurídicas, históricas y culturales, que mostraban la coincidencia de intereses en la concepción que de la historia de España tenían los sublevados y los sectores de la sociedad comprometidos.

Igualmente, cuando Franco designó al Conde de Rodezno ${ }^{14}$ como ministro de Justicia, poniendo éste la condición de que sólo aceptaría el cargo si se derogaba el Decreto de disolución e incautación de bienes de la Compañía y la ley del divorcio y el matrimonio civil, Franco le contestó que precisamente para eso le designaba en el cargo (Algunas noticias sobre España dadas por Monseñor Antoniuti conversando con unos pocos padres de la Gregoriana, 1938) (Carta al R. P. Fernando Gutiérrez del Olmo SJ, 1938a).

¿Cómo se llevó a cabo el proceso de restauración? Los primeros momentos tuvieron lugar a principios de febrero de 1938. Por parte de la Compañía se designó al P. Ignacio Romañá como encargado para las negociaciones ${ }^{15}$. El 5 de febrero de 1938, Gomá escribía al P. Ledochowski para ofrecerle su colaboración en la restauración de la Compañía de Jesús en España. Gomá había tenido noticia de que el proceso se estaba empezando a poner en marcha por boca del propio ministro de Justicia, el Conde de Rodezno, quien había sido nombrado en el cargo hacía 5 días. Rodezno le había pedido consejo para derogar la legislación republicana, insistiendo especialmente en las leyes relativas a la Compañía de Jesús. Señala Gomá que, aunque era consciente de que el P. Romañá trasladaría los puntos de vista de los jesuitas al ministro

14 Navarro, nacido en 1883 y fallecido en 1952. Fue abogado, historiador y político. Respecto a esta última faceta de su persona, mantuvo siempre contacto con los carlistas de Javier de Borbón. Durante la República, fue diputado a Cortes por Navarra por el Partido Vasconavarro y en 1933 por el Partido Tradicionalista. Al estallar la guerra civil se puso a las órdenes del general Mola. En 1937, consiguió que los carlistas se pusieran a las órdenes de Franco, a pesar de las reticencias de sus líderes. Durante las primeras etapas del gobierno de Franco, fue ministro de Justicia y, posteriormente, Consejero Nacional de FET y de las JONS.

15 El P. Romañá fue colaborador del ministro de Justicia D. Rafael Aizpún (CEDA) en el gobierno del 3 de octubre de 1934. Ambos consiguieron que se restituyera la mayoría de los bienes incautados a la Iglesia. Esta es la razón por la que fue el P. Ignacio Romañá el encargado de negociar por parte de la Compañía de Jesús la restauración. Durante los meses de septiembre y octubre de 1937 había estado encargado desde Bruselas por Antoniutti de llevar a buen puerto la repatriación a España de los niños vascos que el Gobierno vasco se había llevado a Bélgica. 
sobre este asunto, no estaba de más que él mismo intercediese en favor de la Compañía. El mismo día que Gomá escribía esta carta al Prepósito General de la Compañía, el arzobispo de Santiago, Tomás Muñiz, hacía una propuesta sobre la restauración de la Compañía de Jesús. En primer lugar, exponía la necesidad de que se hiciese por una ley y no un decreto, al ser varios los ministerios que tenían que devolver propiedades: del Interior, de Hacienda y de Educación Nacional. En segundo lugar, hacía una propuesta del contenido. El preámbulo debía versar sobre el «sectarismo antirreligioso que inspiró el decreto de disolución; la gravedad de la injuria al Romano Pontífice, por haberse tomado como pretexto la obediencia a su autoridad; la injusticia de arrebatar bienes sin indemnización alguna, ni a la Compañía ni a otros legítimos poseedores, pues es cierto que no todos eran de la Compañía; la inhumanidad de dejar sin hogar ni amparo a cientos de ancianos y enfermos». En el articulado se debía derogar el decreto de disolución, reconocer la personalidad jurídica de la Compañía, decretar la devolución de los bienes, disolver el patronato creado por el decreto de disolución para gestionar los bienes arrebatados y ordenar a los ministros que dictaran las disposiciones necesarias para la ejecución de la ley (Andrés-Gallego \& Pazos, 2006b).

El 23 de febrero, el P. Romañá escribía al P. Asistente de la Provincia jesuítica de España, el P. Gutiérrez del Olmo, con el fin de comunicarle que el Conde Rodezno ya se había puesto en contacto con él. En la entrevista que ambos mantuvieron, Rodezno le trasladó su optimismo de una pronta restauración de la Compañía de Jesús, pues el propio Franco le había comunicado que era su «expreso deseo» que se produjera (al igual que la derogación de la legislación vigente contraria a la Iglesia y la religión católica). El optimismo de Rodezno era tal que le propuso que no solo se derogase la legislación republicana en contra de los jesuitas, también todas las disposiciones contrarias a estos desde Carlos III. Las intenciones del ministro no podían ser mejores ya que además quería que todo se hiciese siguiendo el dictado de la Compañía. Romañá, más realista, había respondido que por el momento se derogase el Decreto de la República y la incautación hecha contra sus bienes. Lo demás podía dejarse para una ley posterior sobre Congregaciones. A Rodezno y a Puigdollers, Director General de Asuntos Eclesiásticos, les pareció bien. Romañá explicaba sus razones para actuar así: «Esto propuse porque, en primer lugar, temí que por querer hacer algo demasiado acabado se alargase inmoderadamente la derogación del decreto, urgente y necesaria para poder actuar ahora y para resolver muchísimos conflictos, aun judiciales, que se presentan, debido a que la legislación no ha sido modificada todavía; y en segundo lugar, porque hay que estudiar despacio lo legislado y actuado en el segundo sentido para hacer algo completo. 
Sin embargo, ya en el mismo Decreto que ahora se saque, se puede hacer especial mención de este reconocimiento pleno de la Compañía, que desea se haga el ministro, y que efectivamente no se había logrado nunca en los tiempos últimos, ni después de la última restauración» (Carta al R. P. Fernando Gutiérrez del Olmo SJ, 1938a).

Se siguió la fórmula de redactar un decreto de derogación del Decreto de la República, en el que se restituía la situación anterior a la República y se hacía mención a una futura restitución plena de la Compañía. El texto fue escrito por el P. Romañá, junto a Cirilo Tornos ${ }^{16}$, que sustituyó la fórmula de derogación por la de nulidad, para que así fuesen considerados todos los actos siguientes y disposiciones dictadas, así como todas las incautaciones. Dicho texto se corrigió y estudió y se sometió a la aprobación del ministro de Interior, Serrano Suñer.

Las siguientes noticias del proceso datan del 24 de abril cuando Romañá volvió a escribir al P. Asistente. A pesar de las buenas intenciones del ministro de Justicia, el P. Romañá expresaba cierto temor a la oposición «hábil y capciosa por parte de determinados elementos filtrados, aun en el mismo Gobierno». Al ministro de Hacienda, Amado, lo calificaba como «uno de los más peligrosos»; del ministro de Acción Sindical, González Bueno, decía que procedía de la Institución Libre de Enseñanza (que era como decir la competencia anticlerical de la Compañía de Jesús). Cuando fue presentado el Decreto en el Consejo de Ministros, Franco preguntó si no sería esa materia de Concordato. Los ministros recién citados y otros presentes se apresuraron a asentir con grandes gestos. Lo que sigue lo relata en la carta el mismo P. Romañá:

El Conde de Rodezno contestó enseguida muy cumplidamente diciendo que se fijasen bien en que esto no era materia que pudiera ser concordada, que se trataba de algo de estricta justicia, muy consonante con el sentir católico de España. Nadie encontró razones para oponerse a lo que alegaba. Persistiendo la oposición, dijo el Conde con gesto molesto y el señorío que le caracteriza, al mismo tiempo que se levantaba y marchaba: «pues bien, ahí queda el proyecto de Decreto que he redactado; Vds. lo estudian y el día próximo Vds. verán si se ha de aprobar o no. Yo no lo retiro.» Y lanzó el Decreto sobre la mesa. Se apercibió de ello el Generalísimo y corrió a saludarle y decirle: «pero no se disguste V., por favor, yo le ofrezco que el Decreto se aprueba» (Carta al R. P. Fernando Gutiérrez del Olmo SJ, 1938a).

16 Cirilo Tornos fue un católico preocupado por la defensa de los derechos de la escuela católica, así como de los derechos de los padres en la educación de sus hijos. Desempeño un importante papel durante la II República como presidente de la Confederación de Padres de Familia. 
El P. Romañá fue avisado desde el Ministerio de Justicia del incidente, lo que le llevó a entrevistarse con el Vicepresidente del Gobierno, General Gómez Jordana, y el ministro del Interior, Serrano Suñer. Ambos le indicaron que el Decreto se aprobaría, porque «era lo que sentía hoy España y que deseaban ellos desde el primer momento». Serrano Suñer le sugirió además que el mismo día del siguiente Consejo se entrevistara con Franco. Sería él quien prepararía la entrevista. Sin embargo, llegado el día en que se reunía el Consejo y debía darse la entrevista, Serrano Suñer argumentó que era imposible porque «no había tiempo material». Romañá avisó a Rodezno para contarle lo sucedido y prevenirle, convencido de que «algo había».

En la reunión del Consejo, para sorpresa de Rodezno, tras leer el proyecto de Decreto, Franco volvió a repetir la propuesta de dejar el Decreto para el Concordato, siendo secundado por Amado, Serrano Suñer, el Vicepresidente y el resto de ministros, a excepción de Suances, «buen católico», quien no había asistido. Se inició un duro debate durante más de una hora. Empezó Amado alegando que gran parte de los bienes no podían devolverse en ese momento y que además veía que suponía un trato de favor para los jesuitas, ya que había otros expoliados como la Grandeza de España sobre la que no se había hecho nada. La respuesta de Rodezno fue que la Compañía había sido "perseguida especialmente y la primera por parte de la República» y que por ello era justo hacer con ella mención especial. Añadió que la bandera de la reivindicación de la Compañía era una de las más explotadas por la propaganda nacional y a la que mejor respondía el pueblo. Y añadió que por supuesto haría una ley para la Grandeza y todo aquel que hubiese sufrido a manos de la República.

El Decreto fue rechazado. Rodezno se mostró sumamente molestó, sobre todo con Serrano Suñer, quién había participado en la redacción e incluso había introducido sus propias correcciones. En el mismo Consejo, el ministro del Interior reveló las razones para postergar la cuestión a un futuro concordato (exactamente las mismas que Gomá había sospechado en el retraso de la derogación de la legislación matrimonial) ${ }^{17}$ : «debía dejarse para el Concordato para tener una ficha más, ya que con Roma y su diplomacia

17 La restauración de la Compañía de Jesús se hizo de forma paralela a la negociación sobre la derogación de la legislación matrimonial republicana. Para Gomá, la lentitud en llevarla a cabo se debía a que el Gobierno quería utilizarla como punto de negociación para el reconocimiento diplomático pleno y para un futuro concordato (Andrés-Gallego \& Pazos, 2006d). Casa bien esta idea de Gomá con el hecho de que en durante la negociación de la restauración de los jesuitas, Franco propusiera posponer la cuestión a un futuro concordato. Parece claro que el Gobierno quería guardarse sus propios ases. 
no se podía ir desprevenido». Pero, ¿por qué está desconfianza hacia la Santa Sede?

Tras la finalización del Consejo, Rodezno, visiblemente enfadado, fue a ver a Serrano Suñer a su residencia con el objeto de hacerle ver su perplejidad ante lo sucedido. Éste le pidió perdón y le explicó la razón de su proceder. Al parecer, antes del Consejo, había mantenido una entrevista con Antoniutti quien le habría dicho que el Gobierno se olvidase de obtener el derecho de presentación de obispos, algo que suponía una de sus mayores obsesiones. A este hecho, que era el verdadero problema, el ministro de Interior empezó a sumar otras cosas como lo costoso que había resultado que la Santa Sede reconociera al Gobierno de Burgos, la supuesta permisividad ante la cuestión vasca... Puede decirse que la opinión que había quedado en el Gobierno sobre la diplomacia vaticana no era muy positiva.

La cuestión era que hasta el propio Romañá valoraba la gestión de Antoniutti como errónea en algunos aspectos. A saber, la excesiva intromisión en asuntos internos (como el hecho de que el Estatuto de Cataluña se hubiese derogado) y la proximidad a la influencia de sacerdotes vascos opuestos al Movimiento, lo que sin embargo se contradecía con el testimonio dado por los jesuitas de la Gregoriana tras una conversación con Antoniutti.

Tras desahogarse, Serrano y Rodezno estuvieron hablando sobre el texto del decreto durante dos horas. Finalmente, llegaron a un acuerdo en el que se introducían dos modificaciones más. La primera, que en la Comisión entrase un representante del Ministerio de Hacienda por la Dirección General de Propiedades; la segunda, que se atemperase la devolución de bienes a las necesidades del momento. El texto sería aprobado en el siguiente Consejo o Rodezno dimitiría.

Hasta el 3 de mayo, fecha del Consejo en que se aprobó el Decreto, tanto el Conde Rodezno como el P. Romañá siguieron la estrategia de no hablar con nadie sobre el asunto. El día señalado, cuando le llegó el turno de hablar al ministro de Justicia, lo hizo con las siguientes palabras: «Conforme quedamos en el Consejo anterior, traigo ya corregido y modificado el decreto...». González Bueno (llamado el Institucionista por Romañá) replicó que ese asunto había quedado para Concordato. Le coreó enseguida Amado. La ocasión fue aprovechada por Rodezno para hablar de la persecución sufrida por los jesuitas a manos de las izquierdas, siempre su primer objetivo; de la injusticia que vivía la Compañía en España desde que fuera disuelta una noche con gran conmoción para la nación. Terminó diciendo: «si esto no puede aprobarse inmediatamente yo no tengo fuerzas para seguir en mi puesto. Sería un sacrificio que yo no puedo soportar; pero yo espero que no será así, y que reconociendo la justicia de lo que propongo, se aprobará el Decreto». 
Entonces Franco tomó la palabra y dijo que él pensaba que debía aprobarse, siendo secundado por Serrano. El asunto quedó resuelto. Hubo, sin embargo, que introducir dos modificaciones nuevas en el artículo quinto sobre la devolución de los bienes solicitadas por Amado. Una, que aquellas propiedades que cumpliesen un servicio público no serían devueltas; otra, que los destrozos de la guerra en cualquier propiedad quedarían a cargo de la Compañía de Jesús y que el Estado debería ser indemnizado por las mejoras realizadas en cualquier propiedad cuyo valor hubiera aumentado como consecuencia de estas. Sobre la primera modificación, los edificios afectados eran pocos. La mayoría de las propiedades estaban ya en manos de la Compañía y aquellas que quedaban en la zona republicana cumplían un fin de guerra, por lo que no había nadie que pudiera reclamarlas argumentando el interés público. Sobre la segunda modificación era inútil porque la decisión debía tomarla la Comisión y había que tener en cuenta varias consideraciones: la mayoría de los miembros de la Comisión eran proclives a la Compañía; sólo las mejoras necesarias eran indemnizables; los deterioros eran compensables con las mejoras, por lo que quedaba poco margen para estas; en aquellos casos de bienes que el Estado conservase por ser de interés público, los jesuitas podrían ser indemnizados por el suelo. Sin embargo, estas modificaciones empequeñecían, en palabras de Romañá, el espíritu del Decreto, que era el de devolver a la Compañía sus derechos, con toda esplendidez, y dejaban constancia del paso de Amado con su tacañería (Carta al R. P. Fernando Gutiérrez del Olmo SJ, 1938a).

El Decreto quedó redactado en un Preámbulo y cinco artículos. El Preámbulo ha quedado expuesto más arriba. En cuanto al articulado, se derogaba el Decreto de 23 de enero de 1932 sobre la disolución de la CJ, así como las disposiciones aprobadas para el desarrollo de dicho decreto; se reconocía a la Compañía en España plena personalidad jurídica pudiendo realizar libremente todos los fines propios de su Instituto; el patrimonio de la CJ sería el anterior a la aprobación de la Constitución de 1931, si bien, se ponía como límite en la restitución de los bienes a la CJ, «los casos en que aquella pudiera producir perturbación en los servicios públicos a que hubieren sido destinados dichos bienes».

Para la ejecución del decreto, el Ministerio de Justicia designó una comisión. Sería presidida por el Jefe del Servicio Nacional de Asuntos Eclesiásticos. Además, formarían la comisión cuatro vocales: dos Magistrados y otro representante del Ministerio de Hacienda. Todos eran del agrado del P. Romañá.

El 4 de mayo, Antoniutti escribía a Pacelli dándole cuentas de la aprobación del Decreto y alabando la gestión del Conde Rodezno que había 
conseguido imponerse a las reticencias iniciales del resto de ministros (no entraba en detalles). El 19 del mismo mes, Pacelli respondía a Antoniutti mostrando la complacencia de Pío XI por el Decreto y las razones que lo habían impulsado (Cárcel Ortí, 2018).

El P. Romañá sugirió que escribiese el P. General al Gobierno español dando gracias y haciendo especial mención de gratitud hacia Rodezno (Carta al R. P. Fernando Gutiérrez del Olmo SJ, 1938b) (Carta al R. P. Fernando Gutiérrez del Olmo SJ, 1938c). A la carta del Prepósito General de la Compañía respondió Franco por medio del ministro de Asuntos Exteriores el 9 de junio de 1938: «Su Excelencia el Generalísimo agradece vivamente los fervorosos términos de la carta de Vuestra Reverencia, ofreciendo la cooperación de la Compañía para la restauración cristiana, social y patriótica de España, en la que con tanto tesón y sacrificio estamos empeñados [...]» (Carta del Ministerio de Asuntos Exteriores al Reverendísimo Padre M. Ledochowski, Prepósito General de la Compañía de Jesús, 1938). Posteriormente, existieron otras muestras de mutuo apoyo y agradecimiento entre el Gobierno español y la Compañía de Jesús.

El 6 de junio de 1938, en la Basílica de Loyola, tuvieron lugar los actos oficiales para celebrar la publicación del Decreto de Restitución de la Compañía de Jesús en España. De este acontecimiento se hizo eco La Voz de España, dedicando toda una página en su publicación del 7 de junio. El acto fue iniciativa de la Diputación Provincial de Guipúzcoa y contó con la presencia de los ministros de Justicia y Educación Nacional, un representante de Franco y una gran masa de fieles que acudieron desde diferentes puntos de la provincia: la Orden de su Santo Patrón había vuelto.

\section{CONCLUSIONES}

Del proceso que se llevó a cabo para dar el decreto de restauración se obtienen una serie de conclusiones, imagen fiel de las relaciones IglesiaEstado.

En primer lugar, el deseo de Franco de obtener el apoyo de la Iglesia y de una de sus órdenes religiosas más importantes, tanto a nivel nacional como de sus autoridades. La Iglesia fue el principal respaldo internacional que el nuevo Estado tuvo, tanto durante los años posteriores al conflicto mundial, como en los años del aislamiento que tras el fin de la contienda vinieron para España. 
En segundo lugar, el deseo de la Iglesia y, en concreto, de la Compañía de Jesús, de salvaguardar sus intereses en el nuevo Estado. Ambas, como instituciones terrenales, trataron siempre de que la situación política resultante del conflicto civil les permitiese actuar en libertad. Este anhelo y las fuerzas que pusieron en conseguirlo era explicable si se atiende a la situación en la que la Iglesia había vivido, no solo en los últimos años, sino desde hacía décadas donde la práctica habitual de muchos había sido la quema de conventos e iglesias, así como la persecución de sacerdotes y religiosos.

En tercer lugar, la oposición de ciertos sectores de los sublevados a que la Iglesia adquiriese un papel predominante. Si bien es cierto que la mayoría se definían como católicos, también lo es que muchos veían en la Iglesia un duro obstáculo para sus objetivos políticos.

En cuarto lugar, el deseo de Franco de contentar a todos los elementos que formaban el nuevo Estado. El proceso de restauración de la Compañía de Jesús fue una evidencia más de una realidad que existía dentro del bando de los sublevados: las diferentes tendencias que existieron estaban más de acuerdo en lo que no querían que en lo que querían que fuese el nuevo Estado.

En quinto lugar, el proceso de restauración de la Compañía de Jesús fue un capítulo importante en las relaciones diplomáticas entre la Santa Sede y el Gobierno de Burgos. Relaciones de muy buenos gestos en 1936, muchas esperanzas truncadas por ambas partes en 1937 y de algunos éxitos en 1938.

\section{REFERENCIAS}

Alba, P. (s. f.). España. Despertar religioso. Recuperado de Archivum Romanum Societatis Iesu. (HISPANIA 1015-9).

Algunas noticias sobre España dadas por Monseñor Antoniuti conversando con unos pocos padres de la Gregoriana. (1938, junio 10). Recuperado de Archivum Romanum Societatis Iesu. (HISPANIA 1015-7).

Álvarez Bolado, A. (1976). El experimento del Nacional-Catolicismo. 1939-1975. Madrid: Cuadernos para el diálogo.

- (1989). Año de la Victoria. El P. Joaquín Salaverri, S.I., redactor del mensaje papal del fin de la guerra. Miscelánea Comillas: Revista de Teología y Ciencias Humanas, 47(90), 111-130.

- (1995). Para ganar la guerra, para ganar la paz: Iglesia y Guerra Civil: 1936-1939. Madrid: Universidad Pontificia Comillas.

- (2001). España (1936-1939). En O’Neill, Ch. E., Domínguez, J. M. ${ }^{a}$ (coord.), Diccionario histórico de la Compañía de Jesús: biográfico-temático, II (pp. 1289-1311). Madrid. 
- (2001). La Compañía de Jesús en España entre 1936 y 1989. Estudios Eclesiásticos: Revista Teológica de Investigación e Información, 76(297), 145-191; (298), 383-436.

Andrés Gallego, J. (1984). Pensamiento y acción social de la Iglesia en España. Madrid: Espasa-Calpe.

- (1999). La Iglesia en la España contemporánea, 1936-1999. Madrid: Encuentro.

Andrés-Gallego, J., y Pazos, A. M. (eds.). (2002). Informaciones enviadas a la Santa Sede. 3/III/1937. En Archivo Gomá (Vol. 4, p. 51). Madrid: CSIC.

- (2003). Carta del card. Gomá a mons. Pizzardo. 25/V/1937. En Archivo Gomá (Vol. 5, p. 498). Madrid: CSIC.

- (2004a). Carta personal del card. Gomá al card. Pacelli. 26/VI/1937. En Archivo Gomá (Vol. 6, p. 234). Madrid: CSIC.

- (2004b). Nota crítica del P. Recalde a la Falange comentando un párrafo del Manifiesto y un texto de Manuel Hedilla. 10/VII/1937. En Archivo Gomá (Vol. 6, p. 405). Madrid: CSIC.

- (2005a). Carta de Gomá a Pacelli aportando datos que revelan una mejora de las relaciones entre el gobierno de Franco y la Santa Sede. 1/IX/1937. En Archivo Gomá (Vol. 7, p. 316). Madrid: CSIC.

- (2005b). Carta del card. Gomá al P. Ledochowski. 3/IX/1937. En Archivo Gomá (Vol. 8, p. 51). Madrid: CSIC.

- (2005c). Nota de la Oficina de Información al card. Gomá sobre las actividades e intenciones del grupo denominado «España Cristiana» en París. 22/IX/1937. En Archivo Gomá (Vol. 7, pp. 508-510). Madrid: CSIC.

- (2005d). Nota de la Oficina de Información al card. Gomá sobre un escrito distribuido por la Embajada republicana en Francia. 23/IX/1937. En Archivo Gomá (Vol. 7, pp. 541-542). Madrid: CSIC.

- (2006a). Carta de Gomá al P. Ledochowski. 8/I/1938. Madrid: CSIC.

- (2006b). Carta del card. Gomá al P. Ledochowski ofreciendo su colaboración para restituir a los jesuitas en los bienes confiscados durante la República. 5/II/1938. En Archivo Gomá (Vol. 9, pp. 249-250, 288). Madrid: CSIC.

- (2006c). Correspondencia entre el P. Bayle y el P. Ledochowski. En Archivo Gomá (Vol. 10). Madrid: CSIC.

- (2006d). Informe del card. Gomá sobre el proyecto de Ley de Divorcio. II/1938. En Archivo Gomá (Vol. 9, p. 409). Madrid: CSIC

- (2010a). Carta del Cardenal Gomá al general Fidel Dávila contestándole a una carta anterior y anunciándole su viaje a Roma. 5/XII/1936. En Archivo Gomá (Vol. 1, p. 396). Madrid: CSIC.

- (2010b). Carta del Cardenal Gomá al P. Wladimir Ledochowski dándole algunas noticias de la guerra. 13/IX/1936. En Archivo Gomá. Documentos de la Guerra Civil (Vol. 1, pp. 133-136). Madrid: CSIC.

- (2010c). Carta del P. Francisco Javier Peiró SJ al Cardenal Gomá, informándole de que en Roma no se conoce la verdadera situación de España. 20/XI/1936. En Archivo Gomá (Vol. 1, pp. 330-332). Madrid: CSIC.

- (2010d). Informe del Cardenal Gomá a Secretaría de Estado. 24/X/1936. En Archivo Gomá (Vol. 1, p. 247). Madrid: CSIC.

$B O E, 7$ mayo 1938, p. 7162 s; 4 febrero 1939, p. 670. 
Batllori, M. (1976). Los jesuitas en España durante los siglos XIX y XX. AHSI, 45, 394-403.

- (1986). La Compañía de Jesús entre 1833 y 1945.

Bayle, C. (1937). ¿Qué pasa en España? A los católicos del mundo. Salamanca: Delegación del Estado para Prensa y Propaganda.

Bernecker, W. (1992). La intervención alemana en la guerra civil española, Espacio, Tiempo y Forma, Serie V, $H^{a}$ Contemporánea, 5, 77-104.

Callahan, W. J. (2002). La Iglesia Católica en España (1875-2002). Barcelona: Crítica.

Canal, J. (2007). Exilios: Los éxodos políticos en la Historia de España. Siglos XV-XX. Madrid: Silex.

Cárcel Ortí, V. (ed.) (1994). Actas de las conferencias de metropolitanos españoles (1921-1965). Madrid: Biblioteca de Autores Cristianos.

- (2017). La II República y la Guerra Civil en el Archivo Secreto Vaticano, V. Madrid: Biblioteca de Autores Cristianos.

- (2018). Despacho de Antoniutti a Pacelli. 4/V/1938. En La II República y la Guerra Civil en el Archivo Secreto Vaticano: Vol. VI (pp. 331-333). Madrid: Biblioteca de Autores Cristianos.

Carta al R. P. Fernando Gutiérrez del Olmo SJ. (1938a, febrero 23). Recuperado de Archivum Romanum Societatis Iesu. (HISPANIA 1015-5).

Carta al R. P. Fernando Gutiérrez del Olmo SJ. (1938b, mayo 7). Recuperado de Archivum Romanum Societatis Iesu. (HISPANIA 1015-5).

Carta al R. P. Fernando Gutiérrez del Olmo SJ. (1938c, mayo 9). Recuperado de Archivum Romanum Societatis Iesu. (HISPANIA 1015-6).

Carta del Cardenal Gomá al Cardenal Pacelli. 11/XII/1936. (2010). En Archivo Gomá (Vol. 1, pp. 418-419). Madrid: CSIC.

Carta del Ministerio de Asuntos Exteriores al Reverendísimo Padre M. Ledochowski, Prepósito General de la Compañía de Jesús. (1938, junio 9). Recuperado de Archivum Romanum Societatis Iesu. (HISPANIA 1015-10).

Cuenca Toribio, J. M. (1999). Catolicismo contemporáneo de España y Europa: Encuentros y divergencias. Madrid: Encuentro.

De la Hera Martínez, J. (2002). La política cultural de Alemania en España en el periodo de entreguerras. Madrid: CSIC.

De Frutos Herranz, V. (1939, junio 2). Breve narración del martirio de cuatro de mis compañeros. Recuperado de Archivum Romanum Societatis Iesu. (HISPANIA $1014-15,16,17,18,19)$.

De los padecimientos que los Nuestros de España sufren por Cristo. (1936). Acta Romana, VIII, 557-559.

Dionisio Vivas, M. Á. (2012). Isidro Gomá ante la dictadura y la República: pensamiento político-religioso y acción pastoral. Toledo: Instituto Teológico San Ildefonso.

Encinas, A. (1936, agosto 3). Carta al P. General. Recuperado de Archivum Romanum Societatis Iesu. (HISPANIA 1015-2).

Esteban, J. (1998). Las Constituciones de España, Boletín Oficial del Estado. Madrid: Centro de Estudios Políticos y Constitucionales.

García de Cortazar, F. (2006). Los mitos de la Historia de España. Barcelona: Planeta.

García Ocón, J. (2018). La misión educativa en el Colegio de Areneros (1939-1959). Bilbao: Mensajero. 
González, J. L. y Moreno, A. (2013). La propaganda católica en el extranjero de las dos Españas durante la Guerra Civil (1936-1939): Albert Bonet y Leocadio Lobo. Studia Historica. Historia Contemporánea, 31.

González Calleja, E. (1994). El servicio exterior de Falange y la política exterior del primer franquismo: consideraciones previas para su investigación. Hispania, 54(186), 279-307.

Guerra Campos, J. (1986). La Iglesia en España. Boletín Oficial del Obispado de Cuen$c a, 5$.

La vida en la zona roja. (1940a, junio). Noticias de la Provincia de Toledo, 5, 26-27. Recuperado de a.

La vida en la zona roja. (1940b, julio). Noticias de la Provincia de Toledo, 6, 36-38.

La vida en la zona roja. (1940c, agosto). Noticias de la Provincia de Toledo, 7, 24-27.

La vida en la zona roja. La casa de escritores, de Madrid. (1940a, marzo). Noticias de la Provincia de Toledo, 2, 28-31.

La vida en la zona roja. La casa de escritores, de Madrid. (1940b, abril). Noticias de la Provincia de Toledo, 4, 26-29.

Llanos, J. (1942). Nuestra ofrenda. Los jesuitas de la Provincia de Toledo en la Cruzada Nacional. Apostolado de la Prensa.

Márquez, G. (1936, octubre 2). Relato de la persecución en Toledo. Recuperado de Archivum Romanum Societatis Iesu. (HISPANIA 1014-12).

Marquina Barrio, A. (1978). El Vaticano contra la Cruzada. Historia 16, 22, 39-52.

- (1985). La diplomacia vaticana y la España de Franco (1936-1945). Madrid: CSIC.

Martínez, J. (1936, septiembre 5). Diario del P. Juan Martínez S. J. Recuperado de Archivum Romanum Societatis Iesu. (HISPANIA 1014-11).

Montero Moreno, A. (1999). Historia de la persecución religiosa en España: 1936-1939. Madrid: Biblioteca de Autores Cristianos.

Moreno Cantano, A. C. (2014). Literatura de propaganda religiosa extranjera sobre la Guerra Civil española. Revista internacional de Historia de la Comunicación, $1(2), 42-61$

Nota de A. Encinas SJ. (s. f.). Recuperado de Archivum Romanum Societatis Iesu. (HISPANIA 1015-1).

Nuestra Casa (1984). Madrid: ICAI.

Nuestros mártires. P. Fernández Díaz-Masa. (1940, marzo). Noticias de la Provincia de Toledo, 2, 31-33.

P. José María Alegre. (1940, febrero). Noticias de la Provincia de Toledo, 1, 26-29.

Peña González, J. (2011). En el centenario de AMDG: de Ramón Pérez de Ayala a José María Pemán. Boletín de la Real Academia de Córdoba de Ciencias, Bellas Letras y Nobles Artes, 260, 297-302.

Raguer, H. (2001). El incienso y la pólvora. Barcelona: Península.

Redondo, G. (1993). Historia de la Iglesia en España, 1931-1939. Tomo II: La Guerra Civil, 1936-1939. Madrid: Rialp.

Reig Tapia, A. (1988). La justificación ideológica del alzamiento de 1936. En García Delgado, J. L. (ed.), La II República española: Bienio rectificador y Frente Popular, 1934-1936 (pp. 219-227). Madrid: Siglo XXI.

Revuelta González, M. (2014). La pervivencia del espíritu restauracionista en la Compañía de Jesús. Manresa, 86, 45-58. 
- (2004). Restablecimiento de la Compañía por Franco y actividades de los jesuitas en la zona naciona. En Egido, T. (coord.), Los jesuitas en España y en el mundo hispánico (pp. 361-362). Madrid: Marcial Pons.

Riebling, M. (2016). La Iglesia de los espías: la guerra secreta del Papa contra Hitler. Barcelona: Stella Maris.

Rodríguez, J. (2013). Los Jesuitas contra Galdós y contra la novela y algo más. $X$ Congreso Internacional Galdosiano. Madrid: UAM.

Sueiro, D. y Díaz Nosty, B. (1986). Historia del franquismo. Vol. 1, Sarpe, Madrid: Sarpe.

Ugarte Tellería, J. (1998). La nueva Covadonga insurgente: orígenes sociales y culturales de la sublevación de 1936 en Navarra y el País Vasco. Madrid: Editorial Biblioteca Nueva.

Verd, G. M. (2001). Franco. En O’Neill, Ch. E.; Domínguez, J. M. ${ }^{\text {a }}$ (coord.), Diccionario histórico de la Compañía de Jesús: biográfico-temático, II (pp. 1518-1520). Madrid.

Verdoy, A. (1995). Los bienes de los jesuitas: Disolución e incautación de la Compañía de Jesús durante la Segunda República. Madrid: Trotta.

Vincente, M. (2007). La Guerra Civil española como Guerra de Religión. Alcores. Revista de Historia Contemporánea, 4.

Xavier, A. (1997). Jesuitas mártires. 1934-1939. Barcelona: Esín. 